\title{
Electrosensory pore distribution and feeding in the megamouth shark Megachasma pelagios (Lamniformes: Megachasmidae)
}

\author{
Ryan M. Kempster*, Shaun P. Collin \\ The UWA Oceans Institute and the School of Animal Biology, The University of Western Australia, 35 Stirling Highway, \\ Crawley, Western Australia 6009, Australia
}

\begin{abstract}
The megamouth shark Megachasma pelagios is a rare, large filter-feeding shark. Little to nothing is known of its sensory biology, particularly in relation to its feeding behaviour. We describe the abundance and distribution of ampullary pores over the head and propose that both the spacing and orientation of electrosensory pores enables $M$. pelagios to use passive electroreception to maximise feeding efficiency.
\end{abstract}

KEY WORDS: Ampullae of Lorenzini $\cdot$ Electroreception $\cdot$ Filter feeding $\cdot$ Megamouth shark

\section{INTRODUCTION}

Electroreception is an ancient sense that has evolved independently across the animal kingdom in multiple groups, including agnathan (lampreys), cartilaginous (chimaeras, sharks, skates/rays) and bony fishes (lungfish, coelacanth, polypterids, chondrosteans, teleosts), some amphibians and mammals (Scheich et al. 1986, Collin \& Whitehead 2004, Jorgenson 2005). The multiple and independent evolution of electroreception emphasises the importance of this sense in a variety of aquatic environments (Collin \& Whitehead 2004). The electrosensory system of sharks is comprised of a series of electroreceptors, known as the ampullae of Lorenzini, distributed over almost the entire surface of the head anterior to the first gill slit. It is thought that the major role of the electroreceptors is in the detection of prey (Kalmijn 1971, Raschi et al. 2001, Kajiura et al. 2010), but other functions include the detection of predators, the facilitation of social behaviours (Sisneros et al. 1998) and the ability to orient to and navigate within the earth's magnetic field (Kalmijn 1974, 1978, 1982, Paulin 1995, Montgomery \& Walker 2001).
The megamouth shark Megachasma pelagios is a rare species of shark (Last \& Stevens 2009) and is classified as the sole member of the Family Megachasmidae. Since its discovery in 1976, only a small number of M. pelagios sharks have been observed worldwide, with 50 specimens caught or sighted as of 2010. Unlike other planktivorous sharks such as Cetorhinus maximus (basking shark) and Rhincodon typus (whale shark), M. pelagios is thought to adopt a unique method of filter feeding. Instead of swimming continuously with its enormous mouth wide open, filtering water for plankton and jellyfish, $M$. pelagios is thought to attract prey with a bioluminescent strip along its upper jaw (Taylor et al. 1983) - although this has not yet been supported with histological evidence (Nakaya et al. 2008) - and then engulf it in a single motion, similar to the feeding mechanism of some baleen whales (Compagno 1990, Nakaya et al. 2008). This active method of ingesting prey is thought to be due to the restricted internal gill openings and jaw morphology of $M$. pelagios sharks (Compagno 1990, Nakaya et al. 2008). It is thought that swimming with its mouth open would create a negative pressure, 


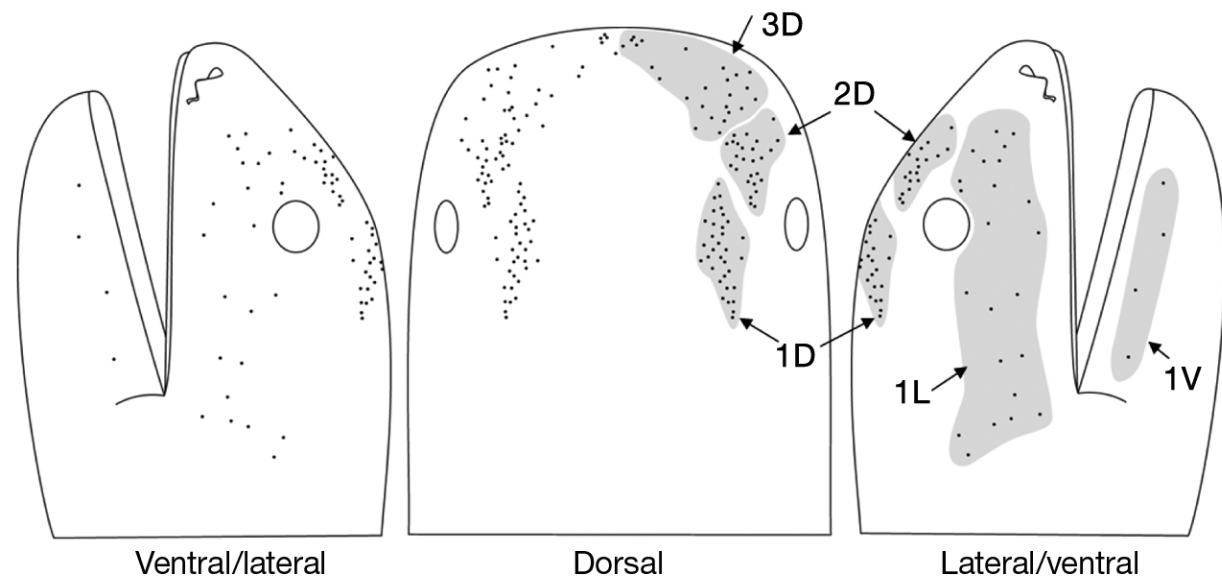

Fig. 1. Megachasma pelagios. Electrosensory pore distribution map for the megamouth shark. D: dorsal; L: lateral; V: ventral whereby water and prey would be pushed aside, due to its densely packed papillose gill rakers and relatively small internal gill rakers (Compagno 1990).

M. pelagios tracked off the coast of California performed vertical migrations with the onset of sunrise and sunset (Nelson et al. 1997). This crepuscular migration allowed $M$. pelagios to consistently sample the water column at a specific level of illumination, with the shark staying at shallow depth at night (12 to $25 \mathrm{~m}$ ) and in the deep during the day (120 to $166 \mathrm{~m})$, but still well above the sea bed, which is at 700 to $850 \mathrm{~m}$ (Nelson et al. 1997). M. pelagios was thought to be following an isolume of 0.4 lux, the same light cue used by its vertically migrating prey (Nelson et al. 1997). As a result, a correlation was found between the diel depth distribution of $M$. pelagios and the vertically migrating krill Euphausia pacifica, which is common in southern California waters (Nelson et al. 1997). The highest night-time concentration of adults and juveniles of E. pacifica was reported to be between the surface and $40 \mathrm{~m}$, with a deeper adult daytime peak located at 200 m (Brinton 1962, Nelson et al. 1997).

\section{MATERIALS AND METHODS}

A specimen of Megachasma pelagios (referred to as Megamouth 3) $5 \mathrm{~m}$ in length was stranded in Mandurah, Western Australia, in 1988 (Berra \& Hutchins 1990). Access to the shark was given during its relocation from the Museum of Western Australia to the Western Australian Maritime Museum in Fremantle. The specimen had been fixed in $70 \%$ ethanol for $22 \mathrm{yr}$ and, although it was apparent that some degree of tissue shrinkage had occurred, the ampullary pores were easily distinguishable from the lateral line pores, given the obvious size difference. Due to limited access to the specimen during this time, the lateral line pores could not be counted and/or their distribution mapped. No dissection of the ampullary pores was allowed, negating any chance of histological analysis. Pores were counted in situ, and photographs were used to produce the pore map presented here, with the aid of a CorelDRAW graphics suite (Fig. 1).

\section{RESULTS}

A total of 225 ampullary pores were present on the head of Megachasma pelagios (Fig. 1), with significantly more pores (75\%) located on the dorsal (D) surface of the head than the ventral $(\mathrm{V}, 4 \%)$ and lateral (L, $21 \%$ ) surfaces combined (25\%; see Table 1$)$. Ampullary pores were found in the most dense assem-

Table 1. Megachasma pelagios. Summary of morphometric data for the specimen Megamouth 3. Ampullary pore abundance for the dorsal (D), lateral (L) and ventral (V) surfaces

\begin{tabular}{|lc|}
\hline & Megamouth 3 \\
\hline $\mathrm{N}$ & 1 \\
Sex & Male \\
Total length $(\mathrm{cm})$ & 515 \\
Body mass $(\mathrm{kg})$ & 690 \\
Ventral pore number & $\mathbf{8}$ \\
1V Left & 4 \\
1V Right & 4 \\
Lateral pore number & $\mathbf{4 8}$ \\
1L Left & 23 \\
1L Right & 25 \\
Dorsal pore number & $\mathbf{1 6 9}$ \\
1D Left & 33 \\
1D Right & 32 \\
2D Left & 28 \\
2D Right & 26 \\
3D Left & 25 \\
3D Right & 25 \\
Total pore number & $\mathbf{2 2 5}$ \\
\hline
\end{tabular}


blages parallel (1D left and 1D right) and anterior (2D left and 2D right) to the eyes on the dorsal surface, with these fields each containing from 25 to 28 pores (Table 1). Pore fields located near the snout (3D left and $3 \mathrm{D}$ right) occupied a larger surface area than the previous 2 fields, but contained a similar number of pores (33 pores; see Table 1). Thus, the pore density of the $3 \mathrm{D}$ left and 3D right fields is much reduced. Pore fields occupying the lateral surface of the head $(1 \mathrm{~L}$ left and $1 \mathrm{~L}$ right) run from behind the posterior margin of the nares, between the eye and jaw line, to just behind the posterior margin of the jaw. The lateral pore fields also contain a similar number of pores to the fields on the dorsal surface (23 to 25 pores; see Table 1), although, as they cover the largest spatial area of the head, they show the lowest pore density of any pore field. Finally, below the jaw line on the ventral surface lie 2 lines of ampullary pores (1V left and $1 \mathrm{~V}$ right) that follow the edge of the jaw on the right and left sides of the head and contain the lowest number of pores of any field (4 pores; see Table 1).

\section{DISCUSSION}

Megachasma pelagios shows the lowest ampullary pore abundance of any shark species currently described and is the only pelagic shark currently known to have almost no pores on its ventral surface (Fig. 1, Table 1). We suggest that the terminal position of the mouth accounts for this unique trait. Most shark species possess sub-terminal mouths and generally do not possess many pores posterior to the lower jaw (Compagno et al. 2004, Cornett 2006). Thus, the lack of pores in this region is not uncommon for sharks, a finding which is also true for the closest living relative of the Megachasmidae, the thresher sharks (Alopidae) (Compagno 1990, Cornett 2006). Taking into account the shape and orientation of the head, with its sloping and rounded surfaces, most of the pore fields are positioned so that they are facing forward, in the direction that $M$. pelagios would be moving. This pore arrangement would allow for the detection of planktonic organisms around the head as the shark swims through the water (horizontally and vertically).

Planktonic prey produce bioelectrical fields of up to $1 \mathrm{mV} \mathrm{cm}^{-1}$, and other species, such as paddlefish, actively hunt for plankton using passive electroreception (Wojtenek et al. 2001). Given that some species of sharks detect electrical fields as weak as $1 \mathrm{nV} \mathrm{cm}^{-1}$ (Kalmijn 1978, 1982, Kajiura \& Holland 2002), Megachasma pelagios may use passive electroreception to determine the presence, and to some degree the abundance, of planktonic prey around its head. In view of the unique feeding mechanism thought to be used by
M. pelagios, it would be beneficial to determine how efficient each feeding event will be before expending the energy to ingest what may possibly just be water with no energetic reward. Therefore, if $M$. pelagios sharks do possess a bioluminescent strip across the upper jaw (Taylor et al. 1983), they would be able to attract planktonic prey and, subsequently, detect their presence with the use of passive electroreception. Each pore receives and processes electrical stimuli independently. Therefore, the signal strength detected at each pore at any given moment would give an indication of the relative concentration and/or location of planktonic prey around the head.

On the other hand, Megachasma pelagios is able to follow migrating prey items (Nelson et al. 1997), a behaviour that could be mediated solely using passive electroreception, potentially negating the need to rely on bioluminescent signals to attract prey. With each scenario presented here, once a desired level of electrosensory stimuli has been achieved, ingestion of prey would then follow using a gulp- and suction-feeding mechanism (Nakaya et al. 2008) to consume all the available planktonic prey in the vicinity of the head, thereby maximising the efficiency of each feeding event.

As the results presented here are based on a single specimen, further work is required to unravel the unique nature of this species' use of electroreception in filter feeding. Given the very sparse and unpredictable availability of Megachasma pelagios specimens, it may be prudent to also focus our attention on the electrosensory systems of more widely available filter-feeding sharks such as Rhincodon typus and Cetorhinus maximus.

Acknowledgements. The authors thank the Endeavour Awards for funding this work, Sue Morrison of the Museum of Western Australia for her continued support, and all those involved with the immense task of moving Megamouth 3 to its new home at the Western Australian Maritime Museum. A big thank you also goes to Channing Egeberg and Caroline Kerr for their invaluable guidance and support throughout this work.

\section{LITERATURE CITED}

Berra TM, Hutchins JB (1990) A specimen of megamouth shark, Megachasma pelagios (Megachasmidae) from Western Australia. Records West Aust Mus 14:651-656

Brinton E (1962) The distribution of Pacific euphausids. Bull Scripps Inst Oceanogr Univ Calif 8:21-270

Collin SP, Whitehead D (2004) The functional roles of passive electroreception in non-electric fishes. Anim Biol 54:1-25

Compagno LJV (1990) Relationships of the megamouth shark, Megachasma pelagios (Lamniformes: Megachasmidae) with comments on its feeding habits. In: Pratt Jr HL, Gruber SH, Taniuchi $\mathrm{T}$ (eds) Elasmobranchs as living 
resources. NOAA Tech Rep 90:357-379

Compagno LJV, Dando M, Fowler S (2004) A field guide to the sharks of the world. Harper Collins, London

Cornett A (2006) Ecomorphology of shark electroreceptors. MS thesis, Florida Atlantic University, Boca Raton, FL

Jorgenson JM (2005) Morphology of electroreceptive sensory organs. In: Bullock TH, Hopkin CD, Popper AN, Fay RR (eds) Electroreception, Vol 21. Springer Handbook of Auditory Research, Springer, Heidelberg, p 47-67

Kajiura SM, Holland KN (2002) Electroreception in juvenile scalloped hammerhead and sandbar sharks. J Exp Biol 205:3609-3621

Kajiura S, Cornett A, Yopak C (2010) Sensory adaptations to the environment: electroreceptors as a case study. In: Carrier JC, Musick JA, Heithaus MR (eds) Sharks and their relatives. II. Biodiversity, adaptive physiology, and conservation. CRC Press, Boca Raton, FL, p 393-429

Kalmijn AJ (1971) The electric sense of sharks and rays. J Exp Biol 55:371-383

Kalmijn AJ (1974) The detection of electric fields from inanimate and animate sources other than electric organs. In: Fessard A (ed) Handbook of sensory physiology, Vol III/3. Springer-Verlag, Berlin, p 147-200

Kalmijn AJ (1978) Electric and magnetic sensory world of sharks, skates and rays. In: Hodgson ES, Mathewson RF (eds) Sensory biology of sharks, skates and rays. Office of Naval Research, Arlington, VA, p 507-528

Kalmijn AJ (1982) Electric and magnetic field detection in elasmobranch fishes. Science 218:916-918

Last PR, Stevens JD (2009) Sharks and rays of Australia. Harvard University Press, Cambridge

Editorial responsibility: Hans Heinrich Janssen,

Oldendorf/Luhe, Germany
Montgomery J, Walker M (2001) Orientation and navigation in elasmobranchs: which way forward? Environ Biol Fishes 60:109-116

Nakaya K, Matsumoto R, Suda K (2008) Feeding strategy of the megamouth shark Megachasma pelagios (Lamniformes: Megachasmidae). J Fish Biol 73:17-34

Nelson DR, McKibben JN, Strong WR, Lowe CG, Sisneros JA, Schroeder DM, Lavenberg RJ (1997) An acoustic tracking of a megamouth shark, Megachasma pelagios: a crepuscular vertical migratory. Environ Biol Fishes 49:389-399

Paulin MG (1995) Electroreception and the compass sense of sharks. J Theor Biol 174:325-339

Raschi W, Aadlond C, Keithar ED (2001) A morphological and functional analysis of the ampullae of Lorenzini in selected galeoid sharks. In: Kapoor BG, Hara TJ (eds) Sensory biology of jawed fishes. Science Publisher, Enfield, $\mathrm{NH}_{\text {, }}$ p 297-316

Scheich H, Langner G, Tidemann C, Coles RB, Guppy A (1986) Electroreception and electrolocation in platypus. Nature 319:401-402

Sisneros JA, Tricas TC, Luer CA (1998) Response properties and biological function of the skate electrosensory system during ontogeny. J Comp Physiol A 183:87-99

Taylor LR, Compagno LJV, Struhsaker PJ (1983) Megamouth-a new species, genus, and family of lamnoid shark (Megachasma pelagios, family Megachasmidae) from the Hawaiian Islands. Proc Calif Acad Sci 43: $87-110$

> Wojtenek W, Pei X, Lon A (2001) Wilkens paddlefish strike at artificial dipoles simulating the weak electric fields of planktonic prey. J Exp Biol 204:1391-1399

Submitted: November 15, 2010; Accepted: December 8, 2010 Proofs received from author(s): January 4, 2011 